\title{
An alarmingly high and increasing prevalence of obesity in Jordan
}

\author{
Kamel Ajlouni', Yousef Khader², Anwar Batieha², Hashem Jaddou², Mohammed El-Khateeb \\ ${ }^{\prime}$ National Center for Diabetes, Endocrinology and Genetics, Jordan University, Amman, Jordan; ${ }^{2}$ Department of Public Health, Jordan University \\ of Science and Technology, Irbid, Jordan
}

OBJECTIVES: The aim of this study was to determine the prevalence of obesity in Jordan, to assess related trends, and to determine associated factors and comorbidities.

METHODS: A multipurpose national household survey of Jordanian adults was conducted over a 4-month period in 2017. Data were collected using a structured validated questionnaire. Anthropometric measurements including waist circumference (WC; measured midway between the iliac crest and the lower rib margin), body mass index (BMI), hip circumference, waist-to-hip ratio, and waist-to-height ratio were obtained to categorize participants with regard to overweight and obesity.

RESULTS: This study included 4,056 persons (1,193 men and 2,863 women) aged 18 years to 90 years (mean \pm standard deviation, $43.8 \pm 14.2$ years). According to the International Diabetes Federation WC criteria, the age-standardized prevalence of obesity was $60.4 \%$ among men and $75.6 \%$ among women, while approximately three-quarters of men and women were overweight or obese as defined by BMI. The age-adjusted odds of obesity in 2017 were approximately twice those in 2009 in men (odds ratio $[\mathrm{OR}], 1.98)$ and women (OR, 1.96). In the multivariate analysis, age, region of residence, and marital status were significantly associated with obesity in both genders. Obesity was significantly associated with increased odds of diabetes mellitus, hypertension, elevated triglycerides, and low high-density lipoprotein cholesterol after adjusting for age.

CONCLUSIONS: The rate of obesity in Jordan is high and increasing, and obesity is associated with other metabolic abnormalities. Well-defined programs to control and prevent obesity, as well as intersectoral action, are urgently required to reverse current trends.

KEY WORDS: Obesity, Prevalence, Epidemiology, Trend, Jordan

\section{INTRODUCTION}

Obesity is a global public health problem in terms of morbidity, mortality, and its associated economic burden. In 2014, 5.0\% of deaths worldwide were attributable to obesity, with an estimated

\section{Correspondence: Yousef Khader}

Department of Public Health, Jordan University of Science and Technology, P.O. Box 3030, Irbid 22110, Jordan

E-mail:yskhader@just.edu.jo

Received: Dec 19, 2019 / Accepted: Jun 6, 2020 / Published: Jun 6, 2020

This article is available from: https://e-epih.org/

(c) This is an open-access article distributed under the terms of the Creative Commons Attribution License (https://creativecommons.org/licenses/by/4.0/), which permits unrestricted use, distribution, and reproduction in any medium, provided the original work is properly cited.

(C) 2020, Korean Society of Epidemiology economic impact of approximately $2.8 \%$ of the global gross domestic product [1]. Obesity is associated with an increased risk of many chronic conditions, including diabetes, dyslipidemia, stroke, cardiovascular disease (CVD), and certain cancers, and it is also associated with an elevated risk of total mortality and death from CVD [2]. Many anthropometric measures, including waist circumference (WC), body mass index (BMI), hip circumference (HC), waist-to-hip ratio (WHR), and waist-to-height ratio (WHtR), have been used as measures of obesity. These measures have been tested, compared, and used to predict the risk of CVD and other metabolic abnormalities. The question of which measure most accurately reflects body fat distribution is still under considerable debate [3].

The prevalence of obesity has doubled since 1980 in more than 70 countries, and obesity affected 107.7 million children and 603.7 million adults worldwide in 2015 [4]. Almost half of the world's 
adult population is predicted to be overweight or obese by 2030 [5]. The prevalence rates of obesity are alarmingly high and increasing in many countries in the Eastern Mediterranean Region (EMR) due to changes in food consumption, reduced physical activity, and an increasingly sedentary lifestyle [6,7]. In adults, the prevalence of obesity increased from $15.1 \%$ in 1980 to $20.7 \%$ in 2015 [8]. The contribution of high BMI to total disability-adjusted life years (DALYs) in the EMR increased from 3.7\% of DALYs in 1990 to $7.5 \%$ of DALYs in 2013 [9].

A survey in 2008 showed that the age-standardized prevalence rate of obesity among adults in northern Jordan was $28.1 \%$ in men and $53.1 \%$ in women. That study also documented an increased rate of obesity in the 10 years preceding the survey [10]. This increase in obesity coincided with increased rates of diabetes, hypertension, and dyslipidemia in Jordan [11-13]. Ten years later, a representative survey using a larger sample size was conducted in the same country. This study aimed to determine the prevalence of obesity in Jordan, to assess related trends, and to determine the associated factors and comorbidities.

\section{MATERIALS AND METHODS}

\section{Study design and sampling}

A multipurpose national household survey was conducted among Jordanian adults over a period of 4 months in 2017. A multistage sampling technique was used to select a nationally representative sample from the population of Jordan. A village or city was selected from each of the 12 governorates of Jordan. The sample of households was chosen in 2 stages. In the first stage, welldefined geopolitical areas were selected from each village or city. The second stage of household selection involved choosing a random sample of households using a systematic sampling technique in each selected area. A team of 2 people (1 woman and 1 man) visited the selected households, explained the study, and invited the members of each household to report to the health center in the selected area after fasting all day. Subjects were asked not to take their medications that day and to bring their medications with them to the health center. Subjects aged $\geq 18$ years were eligible for inclusion in the study.

\section{Data collection}

Data were collected using a structured, validated, and pilot-tested questionnaire administered by trained interviewers. The questionnaire was identical to one used in a 2009 survey. This questionnaire included items intended to assess the socio-demographic variables and clinical characteristics of participants, including selfreported diagnoses and treatment of diabetes and hypertension. Three blood samples were drawn from a cannula inserted into the antecubital vein and used for the laboratory measurements. Tubes containing sodium fluoride potassium oxalate were used for the blood glucose measurement. Samples were centrifuged within 1 hour at the survey site and transferred in separate labeled tubes in ice boxes to the central laboratory of the National Center of Dia- betes, Endocrinology, and Genetics in Amman, Jordan. All biochemical measurements were carried out by the same team of laboratory technicians using the same method. Fasting plasma glucose was measured via the glucose oxidase method using a Roche cobas analyzer (F. Hoffmann-La Roche Ltd., Basel, Switzerland).

\section{Anthropometric measurements}

Several different anthropometric measures-WC, BMI, WHR, and WHtR-were calculated to define overweight and obesity. Weight was measured with subjects minimally clothed without shoes using digital scales (Seca GmbH, Hamburg, Germany). Height was measured using a portable stadiometer (Seca 214, Seca $\mathrm{GmbH}$ ). BMI was calculated as weight in kilograms divided by height in meters squared. WC was measured midway between the iliac crest and the lower rib margin, over light clothing and using unstretchable tape (Seca 203, Seca GmbH), without exerting any pressure on the body surface. WHR was calculated as WC divided by HC, and WHtR was calculated as WC divided by height in centimeters. All measurements were taken by the same team of well-trained persons using the same tools.

\section{Variable definitions}

Overweight and obesity were defined using various criteria and standards. Based on BMI, overweight was defined as a BMI $\geq 25$ $\mathrm{kg} / \mathrm{m}^{2}$ and $<30 \mathrm{~kg} / \mathrm{m}^{2}$, while obesity was defined as a BMI $\geq 30$ $\mathrm{kg} / \mathrm{m}^{2}$. Based on WC, obesity was defined using the Adult Treatment Panel III criteria (WC $\geq 88 \mathrm{~cm}$ for women and $\geq 102 \mathrm{~cm}$ for men) and separately using the International Diabetes Federation (IDF) criteria. As recommended by the IDF criteria, the European cut-off values were used to define obesity among Jordanian adults (WC $\geq 80 \mathrm{~cm}$ for women and $\geq 94 \mathrm{~cm}$ for men). The World Health Organization criteria (WHR $>0.85$ for women and $>0.90$ for men) were used to define obesity based on WHR. Participants were considered to have recently diagnosed diabetes if they had fasting blood sugar $\geq 126 \mathrm{mg} / \mathrm{dL}(\geq 7.0 \mathrm{mmol} / \mathrm{L})$ at the time of the survey with no prior history of diabetes. Participants were considered to have recently diagnosed hypertension if they had a systolic blood pressure of $\geq 140 \mathrm{mmHg}$ and/or a diastolic blood pressure of $90 \mathrm{mmHg}$ at the time of the survey with no prior history of hypertension. Previous diagnoses of diabetes and hypertension were self-reported by participants. Metabolic risk factors were defined using the 2006 IDF criteria, which defined elevated triglycerides as $\geq 150 \mathrm{mg} / \mathrm{dL}(\geq 1.7 \mathrm{mmol} / \mathrm{L})$ and reduced high-density lipoprotein (HDL) cholesterol as $<40 \mathrm{mg} / \mathrm{dL}$ ( $<1.03$ $\mathrm{mmol} / \mathrm{L})$ for men and as $<50 \mathrm{mg} / \mathrm{dL}(<1.29 \mathrm{mmol} / \mathrm{L})$ for women.

\section{Statistical analysis}

Data were entered into and analyzed using SPSS version 20 (IBM Corp., Armonk, NY, USA). Data were described using means and percentages. To permit comparison between the different surveys and with studies in other countries, age-standardized prevalence rates of obesity were derived using the world population as a stand- 
ard. Additionally, 95\% confidence limits were reported for these standardized rates. The chi-square test and crosstabs analysis were used to compare differences between proportions. To assess the changes in the likelihood of obesity between the 2009 and 2017 surveys, the data of both surveys were merged and analyzed after adjusting for age. Binary logistic regression analysis was conducted to determine factors associated with obesity, while other binary logistic regression models were utilized to evaluate the associations

Table 1. Demographic and clinical characteristics of participants

\begin{tabular}{|c|c|c|c|c|}
\hline Characteristics & Men & Women & $\begin{array}{l}\text { Total } \\
\text { (n) }\end{array}$ & $\mathrm{p}$-value \\
\hline Age (yr) & & & & $<0.001$ \\
\hline$<40$ & $335(28.1)$ & $1,208(42.3)$ & 1,543 & \\
\hline $40-50$ & $361(30.3)$ & $855(29.9)$ & 1,216 & \\
\hline$>50$ & $495(41.6)$ & $793(27.8)$ & 1,288 & \\
\hline Region & & & & $<0.001$ \\
\hline Northern & $390(32.7)$ & $922(32.2)$ & 1,312 & \\
\hline Central & $471(39.5)$ & $1,295(45.2)$ & 1,766 & \\
\hline Southern & $332(27.8)$ & $646(22.6)$ & 978 & \\
\hline Type of residential area & & & & 0.023 \\
\hline Rural & $88(7.4)$ & $275(9.6)$ & 363 & \\
\hline Urban & $1,105(92.6)$ & $2,588(90.4)$ & 3,693 & \\
\hline Marital status & & & & 0.001 \\
\hline Single & $144(12.1)$ & $462(16.1)$ & 606 & \\
\hline Married & $1,049(87.9)$ & $2,401(83.9)$ & 3,450 & \\
\hline Nationality & & & & 0.893 \\
\hline Jordanian & $1,117(94.0)$ & $2,669(93.9)$ & 3,786 & \\
\hline Syrian & $71(6.0)$ & $173(6.1)$ & 244 & \\
\hline Smoking & & & & $<0.001$ \\
\hline None & $592(49.6)$ & $2,628(91.8)$ & 3,220 & \\
\hline Past & $206(17.3)$ & $46(1.6)$ & 252 & \\
\hline Current & $395(33.1)$ & $189(6.6)$ & 584 & \\
\hline $\begin{array}{l}\text { Previously diagnosed } \\
\text { diabetes }\end{array}$ & $326(34.6)$ & $433(18.8)$ & 759 & $<0.001$ \\
\hline $\begin{array}{l}\text { Previously diagnosed } \\
\text { hypertension }\end{array}$ & $336(39.2)$ & $614(26.6)$ & 950 & $<0.001$ \\
\hline Elevated triglycerides & $646(54.6)$ & $1,036(36.5)$ & 1,682 & $<0.001$ \\
\hline Low HDL & $727(61.4)$ & $1,649(58.2)$ & 2,376 & 0.057 \\
\hline $\begin{array}{l}\text { High blood pressure or } \\
\text { on antihypertensive } \\
\text { medication }\end{array}$ & $647(54.4)$ & $1,079(38.2)$ & 1,726 & $<0.001$ \\
\hline $\begin{array}{l}\text { High fasting blood sugar } \\
\text { (>100 mg/dL) or on } \\
\text { antidiabetic medication }\end{array}$ & $560(47.4)$ & $940(33.3)$ & 1,500 & $<0.001$ \\
\hline \multicolumn{5}{|l|}{ Physical activity (hr/wk) } \\
\hline Light & $12.7 \pm 14.9$ & $7.5 \pm 10.1$ & & $<0.001$ \\
\hline Moderate & $12.2 \pm 17.7$ & $13.3 \pm 14.2$ & & $<0.001$ \\
\hline Hard & $4.4 \pm 10.8$ & $1.8 \pm 4.8$ & & $<0.001$ \\
\hline $\begin{array}{l}\text { Consumed vegetables at } \\
\text { least } 3 \text { times a day (d/wk) }\end{array}$ & $2.4 \pm 2.4$ & $3.0 \pm 2.7$ & & $<0.001$ \\
\hline
\end{tabular}

Values are presented as number (\%) or mean \pm standard deviation. $\mathrm{HDL}$, high-density lipoprotein. between obesity and metabolic abnormalities. A p-value $<0.05$ was considered to indicate statistical significance.

\section{Ethics statement}

The study was approved by the Ethical Committee at the National Center for Diabetes, Endocrinology, and Genetics in Amman, Jordan. Informed consent was obtained from each participant, and data were treated with strict confidentiality and used only for scientific purposes.

\section{RESULTS}

\section{Participants' characteristics}

This study included a total of 4,056 persons (1,193 men and 2,863 women). Their ages ranged from 18 years to 90 years, with a mean \pm standard deviation of $43.8 \pm 14.2$ years. The demographic and clinical characteristics of the participants according to gender are shown in Table 1. Approximately $41.6 \%$ of men and $27.8 \%$ of women were older than 50 years. Men were significantly more likely than women to have diabetes, hypertension, elevated triglycerides, and low HDL cholesterol. Table 2 shows the means of the anthropometric and clinical parameters for men and women. While men had significantly higher mean WC and WHR, women had significantly higher mean HC, WHtR, and BMI. The mean values of systolic blood pressure, diastolic blood pressure, triglycerides, and fasting blood glucose were significantly higher in men, while the mean values of total cholesterol and HDL cholesterol were significantly higher among women.

\section{Prevalence of obesity}

Table 3 shows the crude and age-standardized prevalence rates of obesity for men and women using various definitions of obesity. Within each gender, the prevalence varied according to the definition used. According to IDF criteria, the age-standardized prev-

Table 2. Anthropometric and clinical parameters by gender

\begin{tabular}{lccr}
\hline Variables & Men & Women & p-value \\
\hline Waist circumference $(\mathrm{cm})$ & $98.9 \pm 15.1$ & $92.7 \pm 16.6$ & $<0.001$ \\
Hip circumference $(\mathrm{cm})$ & $104.7 \pm 11.4$ & $108.3 \pm 13.9$ & $<0.001$ \\
Waist-to-hip ratio & $0.94 \pm 0.09$ & $0.86 \pm 0.11$ & $<0.001$ \\
Waist-to-height ratio & $0.57 \pm 0.09$ & $0.59 \pm 0.11$ & $<0.001$ \\
Body mass index $\left(\mathrm{kg} / \mathrm{m}^{2}\right)$ & $28.4 \pm 4.8$ & $30.0 \pm 6.4$ & $<0.001$ \\
SBP $(\mathrm{mmHg})$ & $127.1 \pm 19.6$ & $118.3 \pm 19.7$ & $<0.001$ \\
DBP $(\mathrm{mmHg})$ & $79.5 \pm 11.7$ & $75.0 \pm 11.6$ & $<0.001$ \\
Total cholesterol $(\mathrm{mg} / \mathrm{dL})$ & $193.3 \pm 45.8$ & $197.5 \pm 41.7$ & 0.004 \\
HDL cholesterol $(\mathrm{mg} / \mathrm{dL})$ & $38.2 \pm 9.5$ & $48.6 \pm 12.3$ & $<0.001$ \\
LDL cholesterol $(\mathrm{mg} / \mathrm{dL})$ & $125.0 \pm 37.3$ & $126.9 \pm 36.3$ & 0.135 \\
Triglycerides $(\mathrm{mg} / \mathrm{dL})$ & $203.8 \pm 209.3$ & $147.3 \pm 110.6$ & $<0.001$ \\
Blood sugar $(\mathrm{mg} / \mathrm{dL})$ & $114.3 \pm 48.6$ & $103.1 \pm 35.9$ & $<0.001$ \\
\hline
\end{tabular}

Values are presented as mean \pm standard deviation. SBP, systolic blood pressure; DBP, diastolic blood pressure; HDL, highdensity lipoprotein; LDL, low-density lipoprotein. 
Table 3. Age-standardized prevalence rates of obesity by gender using different definitions of obesity

\begin{tabular}{lccccc}
\hline \multirow{2}{*}{ Obesity indicator } & \multicolumn{2}{c}{ Men } & & \multicolumn{2}{c}{ Women } \\
\cline { 2 - 3 } \cline { 5 - 7 } & $\begin{array}{c}\text { Crude prevalence, } \\
\%^{1}\end{array}$ & $\begin{array}{c}\text { Standardized rate, } \\
\%(95 \% \text { Cl) }\end{array}$ & & $\begin{array}{c}\text { Crude prevalence, } \\
\%^{1}\end{array}$ & $\begin{array}{c}\text { Standardized rate, } \\
\%(95 \% \mathrm{Cl})\end{array}$ \\
\hline Body mass index $\geq 25 \mathrm{~kg} / \mathrm{m}^{2}$ & 77.3 & $77.2(69.4,74.9)$ & & 77.3 & $74.5(72.9,76.0)$ \\
Waist circumference (IDF criteria) & 67.3 & $60.4(57.6,63.2)$ & & 77.8 & $75.6(74.2,77.0)$ \\
Waist circumference (ATP III criteria) & 41.5 & $36.5(33.8,39.3)$ & & 62.8 & $60.7(59.1,62.2)$ \\
Waist-to-hip ratio (WHO criteria) & 71.8 & $63.4(60.6,66.0)$ & & 48.5 & $47.5(45.8,49.1)$ \\
Waist-to-height ratio (Jordan-specific cut-off values) & 52.1 & $44.2(41.5,46.9)$ & & 49.4 & $47.8(46.2,49.3)$ \\
\hline
\end{tabular}

$\mathrm{Cl}$, confidence interval; IDF, International Diabetes Federation; ATP III, Adult Treatment Panel III; WHO, World Health Organization.

'Men: $41.2 \%$ overweight and $36.1 \%$ obese; Women: $29.1 \%$ overweight and $48.2 \%$ obese.

Table 4. Prevalence of waist circumference-defined obesity by gender according to relevant demographic characteristics

\begin{tabular}{lrrrr}
\hline Variables & Men & p-value & Women & p-value \\
\hline Age $(y r)$ & & $<0.001$ & & $<0.001$ \\
$20-29$ & $41(26.6)$ & & $244(42.3)$ & \\
$30-39$ & $114(64.4)$ & & $447(72.4)$ & \\
$40-49$ & $230(73.5)$ & & $665(88.2)$ & \\
$50-59$ & $222(76.0)$ & & $510(94.1)$ & \\
$60-69$ & $119(77.8)$ & & $244(99.2)$ & \\
$\geq 70$ & $71(74.7)$ & & $83(98.8)$ & \\
Region & & $<0.001$ & & $<0.001$ \\
Northern & $258(66.5)$ & & $753(82.4)$ & \\
Central & $280(59.6)$ & & $921(71.2)$ & \\
Southern & $259(79.2)$ & & $524(84.5)$ & \\
Type of residential area & & 0.555 & & 0.287 \\
Rural & $61(70.1)$ & & $220(80.3)$ & \\
Urban & $736(67.0)$ & & $1978(77.5)$ & \\
Marital status & & $<0.001$ & & $<0.001$ \\
Single & $40(28.2)$ & & $197(43.2)$ & \\
Married & $757(72.6)$ & & $2,001(84.4)$ & \\
Smoking status & & $<0.001$ & & 0.360 \\
None & $406(69.0)$ & & $2,010(77.5)$ & \\
Past & $168(82.4)$ & & $39(84.8)$ & \\
Current & $223(56.7)$ & & $149(80.1)$ & \\
\hline
\end{tabular}

Values are presented as number (\%).

alence of obesity was $60.4 \%$ among men and $75.6 \%$ among women. As defined by BMI, approximately three-quarters of both men and women were overweight or obese. Finally, using the recommended measure of WHtR for the Jordanian population, $44.2 \%$ of men and $47.8 \%$ of women were determined to be obese.

Table 4 shows the prevalence of WC-defined obesity in men and women according to relevant demographic characteristics. In both genders, the prevalence of obesity increased significantly with age. The prevalence varied significantly according to the region of residence and was the lowest in the central region for both men and women. The prevalence did not significantly differ according to the type of residential area (urban vs. rural) in men or women. The variation in the prevalence of obesity according to smoking status was significant among men only.

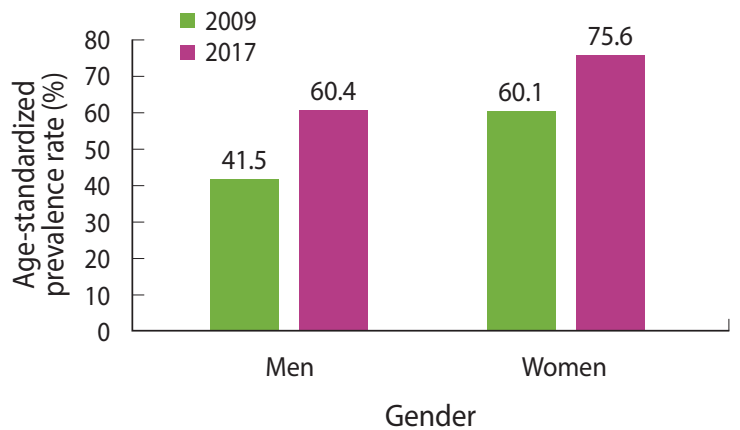

Figure 1. Age-standardized prevalence rates of obesity (defined according to International Diabetes Federation standards) by gender in 2009 and 2017 surveys.

\section{Changes in the prevalence of waist circumference- defined obesity between 2009 and 2017}

The data from the 2009 and 2017 surveys were merged and analyzed to assess the changes in the likelihood of obesity as defined by WC (per the IDF criteria). Figure 1 shows the age-standardized prevalence rates of obesity among men and women in 2009 and 2017 surveys. After adjusting for age, the odds of obesity in 2017 were twice the odds in 2009 in both men (OR, 1.98; 95\% confidence interval [CI], 1.61 to 2.35 ) and women (OR, 1.96; 95\% confidence interval, 1.73 to 2.22 ). In both survey years, the odds of obesity increased with increasing age, peaked at 60-69 years old in both genders, and declined thereafter.

\section{Factors associated with waist circumference-defined obesity}

In the multivariate analysis, age, place of living, and marital status were found to be significantly associated with obesity as defined by WC (per the IDF criteria) among both men and women (Table 5). Older men and women had higher odds of obesity than younger individuals. Compared to men living in the north, those living in the central region had lower odds of obesity, while those living in the south had higher odds. Compared to women living in the north, those living in the central region had lower odds of obesity. Married people had significantly higher odds of obesity than single individuals for both genders. Current smoking 
Table 5. Factors associated with obesity as defined by increased waist circumference (using the IDF criteria) in the multivariate analysis

\begin{tabular}{|c|c|c|c|c|}
\hline Variables & Men & $p$-value & Women & $p$-value \\
\hline \multicolumn{5}{|l|}{ Age (yr) } \\
\hline$<40$ & 1.0 (reference) & & 1.0 (reference) & \\
\hline $40-50$ & $2.0(1.3,2.9)$ & 0.001 & $4.2(3.3,5.5)$ & $<0.001$ \\
\hline$>50$ & $2.3(1.6,3.4)$ & $<0.001$ & $15.0(9.8,22.9)$ & $<0.001$ \\
\hline \multicolumn{5}{|l|}{ Region } \\
\hline Northern & 1.0 (reference) & & 1.0 (reference) & \\
\hline Central & $0.7(0.5,1.0)$ & 0.029 & $0.5(0.4,0.6)$ & $<0.001$ \\
\hline Southern & $2.1(1.4,3.1)$ & $<0.001$ & $1.0(0.7,1.4)$ & 0.939 \\
\hline $\begin{array}{l}\text { Marital status } \\
\text { (married vs. } \\
\text { single) }\end{array}$ & $3.8(2.4,6.2)$ & $<0.001$ & $4.3(3.3,5.5)$ & $<0.001$ \\
\hline \multicolumn{5}{|l|}{ Smoking } \\
\hline None & 1.0 (reference) & & & \\
\hline Past & $1.5(1.0,2.3)$ & 0.066 & - & \\
\hline Current & $0.6(0.4,0.8)$ & $<0.001$ & - & \\
\hline $\begin{array}{l}\text { Hard physical } \\
\text { activity (hr/ } \\
\text { wk) }\end{array}$ & $0.98(0.97,0.99)$ & 0.005 & $0.97(0.96,0.99)$ & 0.003 \\
\hline $\begin{array}{l}\text { Average no. of } \\
\text { daily meals }\end{array}$ & $1.04(1.01,1.08)$ & 0.017 & - & \\
\hline
\end{tabular}

Values are presented as odds ratio ( $95 \%$ confidence interval). IDF, International Diabetes Federation.

among men was significantly associated with decreased odds of obesity relative to non-smokers. In men and women, the odds of obesity decreased significantly as the number of hours spent per week performing hard physical activity increased. The odds of obesity among men increased by $4 \%$ for each additional daily meal.

\section{Metabolic abnormalities associated with waist circumference-defined obesity}

Table 6 shows the metabolic abnormalities associated with obesity as defined by WC (according to IDF criteria) among men and women after adjusting for age. Obesity defined in this manner was found to be significantly associated with increased odds of diabetes mellitus (ORs, 2.1 and 2.9 for men and women, respectively), hypertension (ORs, 2.4 and 2.5 for men and women, respectively), elevated triglycerides (ORs, 2.5 and 4.2 for men and women, respectively), and low HDL (ORs, 2.2 and 2.1 for men and women, respectively) after adjusting for age.

\section{DISCUSSION}

This study demonstrated that the prevalence of obesity in Jordan is alarmingly high in both genders, regardless of the definition of obesity used. Comparing the prevalence of obesity between countries is challenging due to differences in the sampling approaches utilized, age groups included, and anthropometric measures used to define obesity. Since controversy exists regarding which measure most accurately reflects body fat distribution, we used
Table 6. Metabolic abnormalities associated with increased waist circumference by gender after adjusting for age

\begin{tabular}{lcccc}
\hline Variables & Men & p-value & Women & $p$-value \\
\hline Diabetes mellitus & $2.1(1.6,2.8)$ & $<0.001$ & $2.9(2.1,3.9)$ & $<0.001$ \\
Hypertension & $2.4(1.8,3.1)$ & $<0.001$ & $2.5(1.9,3.3)$ & $<0.001$ \\
Elevated triglycerides & $2.5(1.9,3.2)$ & $<0.001$ & $4.2(3.1,5.6)$ & $<0.001$ \\
Low HDL & $2.2(1.7,2.8)$ & $<0.001$ & $2.1(1.7,2.5)$ & $<0.001$
\end{tabular}

Values are presented as odds ratio ( $95 \%$ confidence interval). $\mathrm{HDL}$, high-density lipoprotein.

various measures for obesity in the present study. Furthermore, many previous studies in the EMR region have failed to report standardized rates, which makes comparisons more difficult. Using different measures of obesity and reporting age-standardized estimates would facilitate comparisons between the findings of this study and those of other studies.

The rate of obesity in Jordan is among the highest in the region. High rates have also been reported in other EMR countries, including Saudi Arabia [14] and Kuwait [15]. Half of the global population is predicted to be overweight or obese by 2030 [16]. In 2015 , the prevalence of obesity in the countries of the Organization for Economic Cooperation and Development ranged from less than 6\% in Korea and Japan to greater than 30\% in Hungary, New Zealand, Mexico, and the United States [17]. In 2015, Chooi et al. showed that the prevalence of obesity was $>20 \%$ in many countries, including Germany (20.9\%), Brazil (22.6\%), Argentina (23.2\%), Russia (24\%), the United Kingdom (24.3\%), Turkey (28.5\%), Mexico (28.6\%), South Africa (30.8\%), Iraq (31.9\%), the United States (33.6\%), and Egypt (35.3\%) [18]. The prevalence rates of obesity in the United States and the United Kingdom remained at around 30-34\% and 23-24\%, respectively, between 2005 and 2015 [18]. China witnessed a nearly 9 -fold increase in the prevalence of obesity over the past 35 years, from $0.6 \%$ in 1980 to $5.3 \%$ in 2015 [19].

Per the findings of a previous survey in 2009, the odds of obesity in Jordan in 2017 were approximately twice the odds in 2009 in both men and women after adjusting for age. Lifestyle changes, including the growing consumption of Western-style fast food, reduced physical activity, and an increasingly sedentary lifestyle may explain the increasing rate of overweight and obesity. A similarly increasing trend for obesity has been seen in many countries of the region. The mean BMI and the prevalence of obesity among adults in the EMR increased between 1980 and 2015, possibly due to social and demographic transitions in the area as well as lifestyle changes $[6,9]$.

The prevalence of obesity, even when assessed using different indicators, was found to be greater among women than men in this study. The higher rates among women might be explained by traditional/cultural restrictions in lifestyle choices available to women and limited access to exercise.

The present study showed that married people were more likely to be obese than unmarried individuals. A similar finding was reported in another study in Jordan, which found that the preva- 
lence rates of obesity in married and unmarried adults were 54\% and $37 \%$, respectively [10]. A study in Syria yielded similar results, with obesity prevalence rates of $45 \%$ and $21 \%$ among married and unmarried adults, respectively [20]. Other studies in the region [21-23] have reported similar findings. Marital status has been found to have a mixed relationship with obesity, and the mechanism behind this relationship is poorly understood. The higher odds of obesity among married participants in the present study may be explained by decreases in physical activity, changes in dietary patterns, and a potentially decreased focus on being attractive among married individuals [24-26]. In contrast, unmarried people may pay closer attention to their weight in an effort to appear more attractive to potential marital partners. In married individuals, living in a common household provides social support and can create a responsibility to eat together; this may cause married people to eat more regularly, leading to weight gain [25,27]. This is also supported by our finding that the odds of obesity among men increased by $4 \%$ for each additional daily meal.

The rate of obesity was lower in the central region, where people tend to be higher in socioeconomic status, than in the northern and southern regions. The differences in the prevalence of obesity according to the region of residence may reflect the effects of education level and socioeconomic status on obesity. People with a higher educational level and a higher socioeconomic status may be more concerned about their health and have more positive attitudes toward healthy lifestyles than those with less education or a lower socioeconomic status [27].

In this study, smoking was found to be inversely associated with obesity. This finding is consistent with the results of a number of studies [28,29], although the opposite has also been reported [30]. The relationship between smoking and obesity is complex and not fully understood, and published studies have produced conflicting results.

In conclusion, the rate of obesity in Jordan is high and increasing, and obesity in Jordan is associated with other metabolic abnormalities. If this increase in the prevalence of obesity continues, it could lead to serious health-related outcomes and consequences. Well-defined programs to manage, control, and prevent obesity, as well as intersectoral action, are urgently required to reverse current trends in Jordan.

\section{CONFLICT OF INTEREST}

The authors have no conflicts of interest to declare for this study.

\section{FUNDING}

The study was funded by the Research Fund at the Jordan Ministry of Higher Education.

\section{ACKNOWLEDGEMENTS}

None.

\section{AUTHOR CONTRIBUTIONS}

Conceptualization: KA, YK, AB. Data curation: YK, AB. Formal analysis: $Y K, A B, H J$, MEK. Funding acquisition: KA, YK. Methodology: YK, AB, HJ. Project administration: .KA. Visualization: KA, YK, AB, HJ, MEK. Writing - original draft: YK. Writing - review \& editing: $\mathrm{KA}, \mathrm{YK}, \mathrm{AB}, \mathrm{HJ}$, MEK.

\section{ORCID}

Kamel Ajlouni: http://orcid.org/0000-0001-5569-6306; Yousef Khader: http://orcid.org/0000-0002-7830-6857; Anwar Batieha: http://orcid.org/0000-0001-8639-2807; Hashem Jaddou: http://orcid.org/0000-0001-5590-1576; Mohammed El-Khateeb: http://orcid.org/0000-0002-5201-2287

\section{REFERENCES}

1. Tremmel M, Gerdtham UG, Nilsson PM, Saha S. Economic burden of obesity: a systematic literature review. Int J Environ Res Public Health 2017;14:435.

2. Hruby A, Hu FB. The epidemiology of obesity: a big picture. Pharmacoeconomics 2015;33:673-689.

3. Khader Y, Batieha A, Jaddou H, El-Khateeb M, Ajlouni K. The performance of anthropometric measures to predict diabetes mellitus and hypertension among adults in Jordan. BMC Public Health 2019;19:1416.

4. GBD 2015 Obesity Collaborators, Afshin A, Forouzanfar MH, Reitsma MB, Sur P, Estep K, et al. Health effects of overweight and obesity in 195 countries over 25 years. N Engl J Med 2017; 377:13-27.

5. Dobbs R, Sawers C, Thompson F, Manyika J, Woetzel J, Child P, et al. Overcoming obesity: an initial economic analysis; 2014 [cited 2020 Aug 1]. Available from: https://www.mckinsey.com/ / media/mckinsey/business\%20functions/economic\%20studies\% 20temp/our\%20insights/how\%20the\%20world\%20could\%20better\%20fight\%20obesity/mgi_overcoming_obesity_full_report. ashx.

6. Musaiger AO, Al-Hazzaa HM, Takruri HR, Mokhatar N. Change in nutrition and lifestyle in the Eastern Mediterranean Region: health impact. J Nutr Metab 2012;2012:436762.

7. Rahim HF, Sibai A, Khader Y, Hwalla N, Fadhil I, Alsiyabi H, et al. Non-communicable diseases in the Arab world. Lancet 2014;383: 356-367.

8. GBD 2015 Eastern Mediterranean Region Obesity Collaborators. Burden of obesity in the Eastern Mediterranean Region: findings from the Global Burden of Disease 2015 study. Int J Public Health 2018;63(Suppl 1):165-176.

9. Mokdad AH, Forouzanfar MH, Daoud F, El Bcheraoui C, Moradi-Lakeh M, Khalil I, et al. Health in times of uncertainty in the eastern Mediterranean region, 1990-2013: a systematic analysis for the Global Burden of Disease Study 2013. Lancet Glob Health 2016;4:e704-e713. 
10. Khader Y, Batieha A, Ajlouni H, El-Khateeb M, Ajlouni K. Obesity in Jordan: prevalence, associated factors, comorbidities, and change in prevalence over ten years. Metab Syndr Relat Disord 2008;6:113-120.

11. Khader Y, Batieha A, Jaddou H, Rawashdeh SI, El-Khateeb M, Hyassat D, et al. Hypertension in Jordan: prevalence, awareness, control, and its associated factors. Int J Hypertens 2019;2019: 3210617.

12. Ajlouni K, Batieha A, Jaddou H, Khader Y, Abdo N, El-Khateeb M, et al. Time trends in diabetes mellitus in Jordan between 1994 and 2017. Diabet Med 2019;36:1176-1182.

13. Abujbara M, Batieha A, Khader Y, Jaddou H, El-Khateeb M, Ajlouni K. The prevalence of dyslipidemia among Jordanians. J Lipids 2018;2018:6298739.

14. Al-Baghli NA, Al-Ghamdi AJ, Al-Turki KA, El-Zubaier AG, AlAmeer MM, Al-Baghli FA. Overweight and obesity in the eastern province of Saudi Arabia. Saudi Med J 2008;29:1319-1325.

15. Babusik P, Duris I. Comparison of obesity and its relationship to some metabolic risk factors of atherosclerosis in Arabs and South Asians in Kuwait. Med Princ Pract 2010;19:275-280.

16. Kelly T, Yang W, Chen CS, Reynolds K, He J. Global burden of obesity in 2005 and projections to 2030. Int J Obes (Lond) 2008; 32:1431-1437.

17. Organization for Economic Cooperation and Development (OECD). OECD health statistics; 2017 [cited 2020 Aug 1]. Available from: https://www.oecd-ilibrary.org/social-issues-migration-health/ data/oecd-health-statistics_health-data-en.

18. Chooi YC, Ding C, Magkos F. The epidemiology of obesity. Metabolism 2019;92:6-10.

19. Mi YJ, Zhang B, Wang HJ, Yan J, Han W, Zhao J, et al. Prevalence and secular trends in obesity among Chinese adults, 1991-2011. Am J Prev Med 2015;49:661-669.

20. Fouad M, Rastam S, Ward K, Maziak W. Prevalence of obesity and its associated factors in Aleppo, Syria. Prev Control 2006;2:
85-94.

21. Musaiger AO, Al-Mannai MA. Social and lifestyle factors associated with diabetes in the adult Bahraini population. J Biosoc Sci 2002;34:277-281.

22. Al-Shammari SA, Khoja TA, Al-Maatouq MA, Al-Nuaim LA. High prevalence of clinical obesity among Saudi females: a prospective, cross-sectional study in the Riyadh region. J Trop Med Hyg 1994; 97:183-188.

23. Khashoggi RH, Madani KA, Ghaznawy HI, Ali MA. Socioeconomic factors affecting the prevalence of obesity among female patients attending primary health centers in Jeddah, Saudi Arabia. Ecol Food Nutr 1994;31:277-283.

24. Jeffery RW, Rick AM. Cross-sectional and longitudinal associations between body mass index and marriage-related factors. Obes Res 2002;10:809-815.

25. Averett SL, Sikora A, Argys LM. For better or worse: relationship status and body mass index. Econ Hum Biol 2008;6:330-349.

26. Wilson SE. Marriage, gender and obesity in later life. Econ Hum Biol 2012;10:431-453.

27. Wardle J, Steptoe A. Socioeconomic differences in attitudes and beliefs about healthy lifestyles. J Epidemiol Community Health 2003;57:440-443.

28. Basterra-Gortari FJ, Forga L, Bes-Rastrollo M, Toledo E, Martínez JA, Martínez-González MA. Effect of smoking on body weight: longitudinal analysis of the SUN cohort. Rev Esp Cardiol 2010; 63:20-27.

29. Macera CA, Aralis HJ, Macgregor AJ, Rauh MJ, Han PP, Galarneau MR. Cigarette smoking, body mass index, and physical fitness changes among male navy personnel. Nicotine Tob Res 2011;13: 965-971.

30. Reas DL, Nygård JF, Sørensen T. Do quitters have anything to lose? Changes in body mass index for daily, never, and former smokers over an 11-year period (1990--2001). Scand J Public Health 2009; 37:774-777. 